\title{
AGUSTÍN ESPINOSA. EL MOVIMIENTO DE UNA RECEPCIÓN
}

\author{
Nilo Palenzuela \\ Universidad de La Laguna
}

\section{RESUMEN}

El presente trabajo aborda la recepción de la obra de Agustín Espinosa después de la reedición de 1974 de Lancelot, $28^{\circ}-7^{\circ}$ (1929), Media hora jugando a los dados (1933) y Crimen (1934). Se muestran las aportaciones más importantes y las perspectivas críticas adoptadas. Se aborda, también, la peculiar adopción que hace Espinosa de las estéticas y posiciones cubistas y surrealistas. Este trabajo tiene como perspectiva básica la concepción de durée de Henri Bergson, también readaptada por estudiosos como Vladimir Jankélévitch y, especialmente, por Georges Sebbag en el ámbito de surrealismo y filosofía. La analogía, la duración, la memoria constituyen para Espinosa una manera de interpretar la cultura del pasado y del presente. La durée de Agustín Espinosa desde 1974 hasta la actualidad tiene que ver con sus elecciones y con lo que estaba inscrito en sus palabras como continuidad de una obra y una posición ante la cultura. La "apertura bergsoniana» de su recepción muestra la incidencia de sus elecciones durante las últimas décadas del siglo xx y las primeras del siglo XxI.

Palabras Clave: Agustín Espinosa, vanguardia, surrealismo, recepción, durée, Henri Bergson, Georges Sebbag.

\section{AGUSTÍN ESPINOSA. THE MOVEMENT OF A RECEPTION}

\section{Abstract}

This article studies the reception of Agustín Espinosa's work after the 1974 reissue of Lancelot, $28^{\circ}-7^{\circ}$ (1929), Media hora jugando a los dados (1933) and Crimen (1934). The most important contributions and the critical perspectives adopted are shown. The peculiar adoption by Espinosa of cubist and surrealist aesthetics and positions is also dealt with. The basic perspective of this work is Henri Bergson's conception of durée, also readapted by scholars such as Vladimir Jankélévitch and, especially, by Georges Sebbag in the field of surrealism and philosophy. For Espinosa, analogy, duration and memory constitute a way of interpreting the culture of the past and the present. Agustín Espinosa's durée from 1974 to the present has to do with his choices and with what was inscribed in his words as continuity of a work and a position before culture. The "Bergsonian opening" of his reception shows the incidence of his choices during the last decades of the 20th century and the first decades of the 21th century.

KeYwords: Agustín Espinosa, avant-garde, surrealism, reception, durée, Henri Bergson, Georges Sebbag. 
Georges Sebbag, uno de los pensadores franceses estrechamente relacionado con el surrealismo, escribe en 1997: 207 las palabras que ahora cito y que pertenecen al capítulo "Qu'est-ce qu'une durée?», del libro Le point sublime. Breton, Rimbaud, Kaplan:

Que nous le voulions ou non, nous expérimentons des durées, bien plus que nous n'usons des choses et des mots. Plus rien n'oppose la mort au vivant, l'inerte au mouvant. Passant outre le temps irréversible et segmenté, les durées aimantées du hasard objectif et de l'écriture automatique précipitent les événements, opèrent des rapprochements, imposent des recoupements, mêlant les sortilèges des lieux et de la mémoire, redistribuant les dates des biographies et de l'histoire.

[Nos guste o no, experimentamos duraciones, mucho más de lo que usamos las cosas y las palabras. Ya no hay nada entre la muerte y lo vivo, entre lo inerte y lo que se mueve. Anulando el tiempo irreversible y segmentado, las duraciones magnéticas del azar objetivo y de la escritura automática precipitan los acontecimientos, promueven reconciliaciones, imponen entrecruzamientos, mezclan los hechizos del lugar y de la memoria, redistribuyen las fechas de las biografías y de la historia].

Este horizonte de la durée, de la duración, que deja abolidas las distancias entre la movilidad y la quietud, entre toda suerte de contrarios, y que lleva a borrar fronteras y volver comunicables el espacio y el tiempo, preside esta aproximación que, si no evita nuestras perspectivas anteriores sobre la obra espinosiana, sí las reorienta y permite ver los horizontes que abre el autor en Lancelot, $28^{\circ}-7^{\circ}$, en Crimen, en otros textos. La perspectiva de Georges Sebbag tiene una antesala precisa: el pensamiento que Henri Bergson desarrolló desde el fin de siglo XIx. Sobre esta presencia bergsoniana volveremos más adelante. Baste por ahora señalar que Sebbag ve la durée, la duración bergsoniana, en una dimensión que coincide con el vanguardismo y con el surrealismo.

En efecto, más allá de las relaciones concretas, lo que precede y lo que sigue a la expresión espinosiana prolonga un tiempo de la crítica y de la creación que se expresa con tono subversivo, con gran libertad, como si la durée misma de toda una cultura fuera subvertida, traída a un periodo contemporáneo nuevo: une durée poignardée. Pero antes de llegar ahí, es preciso ver cómo se despliega la obra $y$, aunque solo sea a grandes rasgos, cómo se recibe desde su lectura y desde su prolongación crítica.

Punto de partida. En 1929 la Compañía Iberoamericana de Publicaciones edita Lancelot, $28^{\circ}-7^{\circ}$ en Madrid. En 1933 se publica en Las Palmas de Gran Canaria Media hora jugando a los dados, la conferencia pronunciada en el Círculo Mercantil. En 1934 Ediciones Gaceta de Arte edita Crimen en Santa Cruz de Tenerife. Agustín Espinosa dejará dispersos numerosos artículos en revistas y diarios de estos años. Aparecen entonces algunas reseñas, pero la recepción se despliega con mayor intensidad pasado el tiempo. En la inmediata posguerra, algunos alumnos suyos lo recordarán, entre ellos Sebastián y Antonio de la Nuez Caballero, y Alfonso de Armas Ayala. Este último le dedica el libro Espinosa, cazador de mitos, que da a conocer en 1960 el Instituto de Estudios Hispánicos del Puerto de la Cruz. 
1974 es la fecha fundamental para iniciar un discurso sobre la recepción de Agustín Espinosa. El poeta Manuel Padorno y Josefina Betancor publican en Madrid, en Ediciones JB, Lancelot, $28^{\circ}-7^{\circ}$, Crimen y Media hora jugando a los dados, las tres obras publicadas por Espinosa cuarenta años atrás. El autor volvía a estar presente. Lo hacía, además, en una época de vindicaciones políticas y movimientos críticos que deshacían la fortaleza de la dictadura de Francisco Franco. El libro de Josefina Betancor y Padorno coincidía en un entorno editorial donde podría encontrarse toda suerte de ediciones, semiclandestinas algunas, importadas otras, de filosofía marxista-leninista, maoísmo y de cualquier otro discurso ajeno a la ideología reinante. La recuperación de Espinosa convivía con las expectativas de libertad democrática, con la melancolía de una época republicana, a menudo idealizada. Y todo comienza a partir de ahí, con algunos precedentes y con algunos testigos que evocan aquel pasado a la altura de los setenta, algo casi remoto para las nuevas generaciones.

En 1968 Eduardo Westerdahl, el crítico de arte, que fue director de la revista Gaceta de Arte (1931-1936), da a conocer en Gustavo Gili, en Barcelona, su monografía Óscar Domínguez. En 1975, Tusquets Editores publica Facción española surrealista de Tenerife, de Domingo Pérez Minik. En 1979, Sebastián de la Nuez Caballero pone a la vista La Rosa de los Vientos (1927-1928), en una edición facsimilar. La recuperación de los escritores y artistas se despliega desde entonces, donde destaca la publicación espinosiana de Ediciones JB. Eugenio Padorno se ocupa de Juan Ismael; Lázaro Santana, de la Escuela Luján Pérez; Fernando Castro Borrego vuelve, a la estela de Westerdahl, a Óscar Domínguez; Miguel Pérez Corrales estudia y edita a Espinosa; Andrés Sánchez Robayna y Brian Morris, a Domingo López Torres; por mi parte recupero artículos y obras desconocidas de Pedro García Cabrera; Isabel Castells se ocupa de Emeterio Gutiérrez Albelo; M. Isabel Navarro investiga la vertiente arquitectónica de Gaceta de Arte. Sobre esta revista, y sobre Westerdahl y Óscar Domínguez, Pilar Carreño aportará trabajos decisivos en estas últimas décadas; Josefa Alicia Jiménez se ocupa de José Jorge Oramas, el pintor al que dedica Espinosa Media hora jugando a los dados. Así, numerosos investigadores aportan visiones, datos, perspectivas nuevas: Jorge Rodríguez Padrón, Carlos Eduardo Pinto, Federico Castro Morales, Ángeles Abad, Ángel Sánchez, Juan Cruz, Fernando Martín, José Manuel Martín Fumero; o el mismo Eugenio Padorno, que en 2000 vuelve a editar Crimen. Media hora jugando a los dados en Libros del Innombrable, de Zaragoza. Durante los años ochenta, asimismo, la revista Sytanxis y el suplemento Jornada Literaria, y las revistas Papeles Invertidos, Liminar y LC, insistieron, con mayor o menor eficacia, en este proceso de recuperación.

Agustín Espinosa está en el centro de esta vuelta a la época de las vanguardias. Y las investigaciones de Miguel Pérez Corrales constituyen el impulso central en lo que ha venido a ser la continuada recepción de su obra. Solo unos datos relacionados con Pérez Corrales: en 1980 el Aula de Cultura de Tenerife publica su Agustín Espinosa. Textos (1927-1936), que aparece firmado junto con Alfonso Armas Ayala. En 1985 Interinsular Canaria da a conocer su edición crítica de Crimen. En 1986, las Ediciones del Cabildo Insular de Gran Canaria publican los dos volúmenes de la amplia investigación emprendida años antes en la Universidad de Barcelona: Agustín Espinosa, entre el mito y el sueño. Ediciones, estudios, intervenciones diversas ha prodi- 
gado Miguel Pérez Corrales. Toda la información actualizada de la recepción, junto con los textos completos de Agustín Espinosa (salvo la obra fascista, que coincide con el proceso de depuración al que es sometido durante la guerra civil española), se encuentra hoy a disposición del lector, donde quiera que habite. Desde 2018-2019 puede consultarse de forma abierta y gratuita en su blog Espinosa, obra en libertad. Asimismo, el amplio panorama del surrealismo internacional, junto con libros tan importantes como Caleidoscopio surrealista, pueden encontrarse en el blog Surrealismo internacional, de Pérez Corrales. De la misma manera debe señalarse que este profesor -y escritor- ha ofrecido considerable apoyo a los nuevos investigadores. Un solo ejemplo, reconocido por la propia autora: así se muestra en Les mythes et leurs métamorphoses dans l'oeuvre d'Agustín Espinosa (1897-1939), de Beatriz Gómez Gutiérrez, la tesis defendida y editada en 2008 en la Université Paris-Sorbonne. Gómez Gutiérrez, cabe recordar, fue alumna de Eugenio Padorno en la Universidad de Las Palmas de Gran Canaria.

Agustín Espinosa es conocido, por otro lado, en otras lenguas. En 1989, Éditions de la Différence edita Crime en traducción francesa de Gérard de Cortanze; en 2008 se traduce Lancelot, $28^{\circ}-7^{\circ}$ al alemán; y, en 2017, Crimen, Poemas a Mme. Josephine y Oda a María Ana se trasladan al portugués en edición brasileña. Con las traducciones y con la labor de Miguel Pérez Corrales el arco de difusión abierto por Josefina Betancor y Manuel Padorno ha recorrido una amplia trayectoria.

Podemos entonces hablar de perspectivas críticas, de ciertas durées interpretativas introducidas por Agustín Espinosa o sobre Agustín Espinosa. Las lecturas postreras, un siglo más tarde de la redacción de sus primeros poemas, no dejan de mostrar motivos de una prolongada duración que viene de lejos, y que irá más lejos. Avancemos, aunque solo sea brevemente en este proceso. Hagámoslo siguiendo cierto orden, aun cuando los apartados que siguen mantienen estrechas relaciones entre sí. Veámoslo a través de la recepción, pero también desde la actitud creadora de Agustín Espinosa, siguiendo este orden: la perspectiva histórica y comparatista, palimpsesto y ejercicio hermenéutico y, finalmente, desde lo que podemos llamar «apertura bergsoniana».

Los amplios trabajos de Pérez Corrales han mostrado los aspectos importantes de la obra de Agustín Espinosa y su propia trayectoria vital. Sus ediciones, sus artículos y sus libros han discernido sobre el contexto literario español, sobre la manera de moverse entre clásicos y contemporáneos, sus peripecias vitales, su viaje por Europa, sus periplos insulares, sus colaboraciones aquí, allá, sus amigos, sus polémicas. Pérez Corrales ha avanzado, junto con la vertiente histórica y comparatista, en la vertiente dialógica de los textos espinosianos, en sus tradiciones, en su reencuentro con escritores como Rosalía de Castro, Larra, Bécquer, Juan Ramón Jiménez, Ramón Gómez de la Serna, Eugenio D’Ors, Ernesto Giménez Caballero; también en las relaciones de pensamiento y escritura con destacados precursores, los románticos europeos, o Dostoievski, Lautréamont, Baudelaire; o con sus contemporáneos surrealistas, André Breton, Paul Eluard, Benjamin Péret... También ha establecido las relaciones de Espinosa con el arte surrealista, El gran masturbador de Dalí con el comienzo de Crimen, otros motivos con los cuadros de René Magritte. Por así decir, la actividad crítica de Pérez Corrales en el terreno historiográfico, en 
el espacio comparatista y en el terreno del diálogo intertextual ha devuelto a Espinosa al presente, señalando motivos, temas, textos, imágenes, recursos... que, si se fundaron desde 1929 a 1934 -por solo señalar las fechas paradigmáticas de su obra-, salen de la memoria de la elaboración textual para prolongar su sentido en una obra que se desliza, por muy anclada que pareciera en su época, hacia el pasado y hacia el porvenir.

Por nuestro lado, de forma no excesivamente lejana, en nuestra edición de Lancelot, $28^{\circ}-7^{\circ}(1988)$ planteamos su relación con el dominio creativo del cubismo y con la voluntad de la création que definían los postulados estéticos de la revista Nord-Sud (1917-1918), la revista dirigida por Pierre Reverdy. En efecto, ahí se muestra con claridad cómo desde Georges Braque a Paul Dermée, los postulados estéticos dejaban atrás todo principio de imitación, al tiempo que la idea de interpretación presente en el arte y la literatura del siglo XIX (simbolismo, impresionismo). Se optaba entonces por un ideal como el que Espinosa quiso: una isla inventada por la escritura y el arte. La analogía en la aproximación súbita de realidades diversas y el simultaneísmo recorren las páginas de Lancelot, $28^{\circ}-7^{\circ}$, así desde la cita inicial de Paul Dermée a la yuxtaposición de visiones que parten de Lanzarote hasta constituir una mirada de conjunto repleta de vínculos sorprendentes.

Señalamos también la compleja elaboración que vuelve contemporáneos temas, escrituras, posiciones diversas. Recuerdo solo unos detalles. En el capítulo dedicado a Mozaga, Espinosa se hace eco del motivo de los dados y del cubilete, de tan clara ascendencia estética francesa. En 1914 La Nouvelle Revue Française había publicado el fragmentario Un coup de dés, de Stéphane Mallarmé. Los vanguardistas, que ya no estaban para excesiva elaboración metafísica, prefieren la simple evocación del juego de los dados. Pablo Picasso realiza Nature morte à la pipe et aux dés en 1914. Y Max Jacob edita en 1917 Le cornet à dés, sus fragmentos en prosa, traducidos por Guillermo de Torre para la madrileña Editorial-América en 1924: El cubilete de dados. Espinosa, colaborador de La Gaceta Literaria desde 1927, tuvo cerca a Guillermo de Torre, primer secretario de aquella publicación. Naturalmente conocía el libro. Y también la nueva sensibilidad. Su personaje poético Lancelot venía así a elaborarse sobre la memoria de héroes caballerescos, del personaje cervantino enloquecido de lecturas, de héroes clásicos y homéricos, pero también bajo la estética cubista y poscubista. Lancelot jugaba a los dados.

Dicen que Atlante. Bueno. Pero yo he creído siempre que Lancelot. Cojo ya $-\mathrm{y}$ ciego- ¡qué doloroso su caminar por la noche vasta de sus días! Relleno su pretérito de auroras de lector solitario. Sobre todos sus pesares pesaba el gran pesar de no poder jugar a los dados. ¡Su único juguete del otoño! Lloró largamente sobre el cuero y el marfil inútiles. Empuño el cubilete y lanzó los dados a los aires.

Así, Nazaret y Mozaga. Dados del mismo cubilete las casas de Mozaga y de Nazaret. Aún se aprecian en las casas Nazaret y Mozaga las huellas dactilares del magno señor (Espinosa 1988: 29-30).

Agustín Espinosa apura toda suerte de analogías y referencias, de Atlante y los héroes homéricos, de Lancelot y el Quijote, pero ¿por qué crece la imagen de un ser gigantesco ante las casas de Mozaga y de Nazaret, convertidas en dados? Contes- 
tamos a ello en 1988: Espinosa piensa en Luis de Góngora y Fábula de Polifemo y Galatea, en aquella hora del centenario de 1927 tan celebrado por los vanguardistas, compartido por La Rosa de los Vientos y Litoral, por Carmen y Lola, por La Gaceta Literaria. Sobre Góngora venía insistiéndose desde hacía años (Palenzuela 1994). Lo que Espinosa hace es dar una vuelta más al simultaneísmo sobre una base de evidente palimpsesto. Meses antes de la aparición del libro en Madrid había redactado así el fragmento de Mozaga, el mismo que acabamos de reproducir, solo que con variantes que ponemos en cursiva:

Dicen que Atlante. Bueno. Pero yo he creído siempre que Polifemo. Tuerto ya $-\mathrm{y}$ ciego- ¡qué doloroso su caminar por la noche vasta de sus días! Relleno su pretérito de auroras de pastor solitario. Sobre todos sus pesares pesaba el gran pesar de no poder jugar a los dados. ¡Su único juguete del otońo! Lloró largamente sobre el cuero y el marfil inútiles. Empuñó el cubilete y lanzó los dados a los aires.

Así, Nazaret y Mozaga. Dados del mismo cubilete las casas de Mozaga y de Nazaret. Aún se aprecian en las casas Nazaret y Mozaga las huellas dactilares del magno pastor (Espinosa 1988: 105-106).

Así actúa Espinosa: Lancelot fue antes Polifemo. Así Espinosa se desplaza sobre la memoria y trae más acá en una escritura creadora y crítica que vuelve simultáneos instantes y espacios, motivos antiguos y modernos, personajes de aquí y de allá. A veces deja a la vista sus puntos de partida, sus audacias; otras, como en las palabras citadas, se desvela con qué libertad actúa, cómo la analogía cubista podía convivir con el personaje recreado por Góngora con desmesura hiperbólica.

Agustín Espinosa también actúa así en sus textos críticos, en el fondo no excesivamente distantes de su manera creativa de proceder. El intérprete se vuelve mediador que descifra signos, establece similitudes, sitúa en el tiempo símbolos, signos, enigmas. El intérprete se vuelve hermeneuta, interpreta, pero también orienta e interroga sobre el origen y sobre el fin. Acoge además el sentido de hermeneusis sugerido desde el Renacimiento y desarrollado en el siglo xx a partir del pensamiento heideggeriano: contribuye a fundar una realidad. Sobre ello hemos insistido en un viejo texto de comienzos de los ochenta; y a ellos volvimos con mejor criterio más adelante (Palenzuela 2006: 117-156.). No insistiré ahora en lo que hizo en «La infantina de Nivaria» y la conversión en contemporáneas de las más disímiles referencias, en aquel convertir en contemporáneos antiguos y modernos, algo que en 1988 nos condujo a evocar el imagism anglosajón y a Ezra Pound.

Veámoslo ahora simplemente en una de las hojillas que Agustín Espinosa esboza para el texto "Tres mitos canarios». Veamos las anotaciones 15 y 16 (Corrales 1986 II: 774). Junto a ellas, una visión geométrica, visual: un triángulo central en cuyos vértices aparecen los nombres de Hércules, Dácil y Peraza; a la izquierda, unidos por el mismo vértice de Hércules, otro triángulo en líneas discontinuas, en que aparece Atlante, arriba, Héspero, abajo; a la derecha, partiendo del vértice de Peraza, otro triángulo con líneas discontinuas, Garcilaso, arriba; Manrique, abajo. Se trata de una síntesis visual y simultánea que aúna diversas épocas y distintos autores: a la derecha, el mundo medieval y renacentista. Guillén Peraza, objeto de la conocida endecha, que murió en La Palma de una pedrada, como Garcilaso, y 
la reminiscencia de Coplas a la muerte de su padre. A la izquierda, las referencias clásicas. Las anotaciones son precisas y muestran la agilidad crítica y poética que tiene Espinosa para unir autores, lugares y fechas diferentes. ¿Es una simple coincidencia con los imagistas ingleses y americanos, con T.E. Hulme, con Ezra Pound, es algo más que la mirada "geométrica» del simultaneísmo cubista? En cualquier caso, nos basta por ahora trasladar aquí sus palabras.

15. Héroes de nuestra historia. Lo geométrico del siglo xviII. Viera ve en triángulos. Hércules, el extranjero del mito. Se lleva las manzanas [del jardín de la Hespérides]. Triunfa en todos sus trabajos.

Peraza, vencido en el primer trabajo.

Dácil. Mira a los dos desde la cima de su ángulo. Mira hacia Hércules, lo mitológico, lo ideal, y hacia Peraza, la realidad dolorosa. Poesía y verdad, goethianas. Al que espera es a Guillén. Por él mira hacia el mar y cuenta velas latinas y cuida su cuerpo y su alma.

Peraza representa al caballero triste del Greco.

16. La pregunta sin respuesta. El viaje de Ulises. (Infierno: Círculo 8, foso $8^{\circ}$ ). Curiosidad vieja. ¡Viera, tan humanista, trad. de griegos y latinos!

Espinosa, entonces, como en «La infantina de Nivaria» o como en Lancelot, reinterpreta textos, establece analogías entre unos y otros, hace simultáneas referencias, épocas, artistas, autores. Los vuelve contemporáneos. Como vamos sugiriendo, no otra cosa hicieron, a pesar de la distancia cultural, las peculiares vanguardias anglosajonas, con T.E. Hulme, animador del imagism y traductor de Bergson, con Ezra Pound, que también podía hacer contemporáneos los versos de Dante o de Guido Cavalcanti. Agustín Espinosa camina, con extraordinaria intuición creadora, por la estela de la durée. Y lo hace desde un espacio atlántico que conoce sus antecedentes, su necesidad de crear una mitología identitaria, en una cultura que se desplaza hacia Occidente con origen bien distinto al grecolatino. Espinosa, apenas siete años después de que se publicara la segunda entrega de Las Rosas de Hércules, de Tomás Morales (1919-1922), persiste en la creación de una mitología, en la creación de una difícil duración espaciotemporal.

Nuestro texto avanza sobre la idea de la durée, de perspectiva bergsoniana, que reorienta los diversos accesos que hemos hecho a la obra de Espinosa durante varias décadas. La perspectiva actúa en el territorio de la crítica y la hermeneusis y, de igual forma, en la creación de textos tan subversivos como Crimen. Las preocupaciones por las relaciones de tiempo y espacio, de memoria y materia, la conjunción tiempo-espacio, la referencia al simultaneísmo y aun a la "cuarta dimensión» las expresa tempranamente Henri Bergson en su tesis de 1889 Essai sur les données immédiates de la conscience y, en 1896, en Matière et mémoire. Citemos varios fragmentos para mostrar lo que entiende por una durée que insiste en la reactivación constante de hechos, imágenes, datos, en un presente que siempre se extiende hacia atrás o se prolonga hacia el futuro. "Toute perception occupe une certaine épaisseur de durée, prolonge le passé dans le présent, et participe par là de la mémoire» (Matière et mémoire 2011 : 293) [Toda percepción ocupa un cierto espesor de duración, prolonga el pasado en el presente, y participa por eso de la memoria]. El Essai 
sur les données immédiates de la conscience deja suficientes variantes de su manera de entender el tema:

Nous projetons le temps dans l'espace, nous exprimons la durée en étendue, et la succession prend pour nous la forme d'une ligne continue ou d'une chaîne, dont les parties se touchent sans se pénétrer. Remarquons que cette dernière image implique la perception, non plus successive, mais simultanée, de l'avant et de l'après (Essai... 2011: 92).

[Proyectamos el tiempo en el espacio, expresamos la duración como extensión, y la sucesión cobra para nosotros la forma de una línea continua o de una cadena cuyas partes se tocan sin penetrarse. Observemos que esta última imagen implica la percepción, ya no sucesiva sino simultánea, del antes y el después].

Puede hablar aquí de simultaneísmo o de cuarta dimensión: "Une quatrième dimension de l'espace, que nous appelons le temps homogène, et qui permet au mouvement pendulaire de se juxtaposer indéfiniment à lui-même» (Essai: 99) [una cuarta dimensión del espacio, que llamamos el tiempo homogéneo y que permite al movimiento pendular, yuxtaponerse indefinidamente a sí mismo]. En un tono que Espinosa parece evocar mucho más tarde, Bergson muestra la experiencia espaciotemporal a través del movimiento de una mano:

Quand, les yeux fermés, nous promenons la main le long d'une surface, le frottement de nos doigts contre cette surface et surtout le jeu varié de nos articulations nous procurent une série de sensations, qui ne se distinguent que par leurs qualités, et qui présentent un certain ordre dans le temps (Essai: 90-91).

[Cuando, con los ojos cerrados, paseamos la mano a lo largo de una superficie, la frotación de nuestros dedos contra esa superficie, y sobre todo el variado juego de nuestras articulaciones nos procuran una serie de sensaciones que sólo se distinguen por sus cualidades y que presentan un cierto orden en el tiempo].

Superficies, acumulación de sensaciones e imágenes, de recuerdos e instantes, tiempos por un momento solidificados cuando se recuerdan o narran. Solidifier es la metáfora que utiliza: «Nous tendons instinctivement à solidifier nos impressions, pour les exprimer par le langage» (Essai... 2011: 117). Cada experiencia, cada evocación, cada imagen, cada dato para el espíritu, por sensorial que sea, táctil o musical, arrastra consigo lo que viene del pasado y también lo que advendrá. En la escritura o en el recuerdo por un instante se cristalizan, se solidifican, para enseguida emprender su curso. Sonidos de campanas, experiencias olfativas y táctiles, o recuerdos, esta idea de la duración surge a finales del siglo XIX y se prolonga en las primeras décadas del siglo a través de los libros, de encuentros con Bergson, o de sus clases en la Sorbona. El pasado reaparece, la experiencia retorna, la memoria se despliega entre súbitas analogías..., el pensamiento también penetra en el arte. T.E. Hulme entablaría una importante relación con Bergson, que concluiría en traducciones al inglés. Al encuentro de Bergson también marchan a París Antonio Machado o T.S. Eliot. Las intuiciones y las ideas bergsonianas calan en un dominio 
estético por donde Espinosa va a transitar, ya desde la ladera vanguardista, cubista o surrealista.

El historiador de arte Serge Fauchereau, que ha hablado de Espinosa y aun ha traducido algún leve fragmento de Crimen (Fauchereau 2002: 411), destaca la huella bergsoniana en el cubismo y recuerda cómo los artistas Albert Gleizes y J. Metzinger señalaron que «le tableau règne dans la durée» (Fauchereau 2012: 74). En Avant-gardes du XX siècle. Arts \& Littérature. 1905-1930 destaca la huella de Bergson en el expresionismo alemán y de forma destacada en el imagism anglosajón, especialmente en T.E. Hulme, en Ezra Pound y en sus concepciones de la imagen (Fauchereau 2010: 55, 167-168, 198-199). De manera específica Alexandre Thibault ha realizado, sobre «la durée bergsonienne» en cubismo y futurismo, la investigación de La durée picturale chez les cubistes et futuristes comme conception du monde: suggestion d'une parenté avec le problème de la temporalité en philosophie (Thibault 2006). Los distintos momentos del desplazamiento de una imagen, su duración, son entrevistos aquí desde el ángulo filosófico, y también plástico. Thibault reflexiona y cita aquí cuadros y esculturas con movimientos casi simultáneos de figuras, objetos, paisajes, piezas de Delaunay, Duchamp, de Metzinger, Boccioni... Aquí se reproduce La mano del violinista, de Giacomo Balla, esa mano que se mueve entre leves intervalos, en ese gesto sucesivo, que está en Bergson y que estará en Espinosa. Balla evidencia las preocupaciones sobre las relaciones espacio-tiempo entre los primeros vanguardistas europeos.

La durée bergsoniana sigue su curso, en las relaciones sobre el cine, o desde diversas orientaciones filosóficas. Podemos hallar su presencia en los discursos de Gilles Deleuze, de Vladimir Jankélévitch, de Emmanuel Lévinas... Su huella está antes en el surrealismo. Y es aquí, en el surrealismo, donde brota el pensamiento de Georges Sebbag, que estuvo inicialmente relacionado con el grupo de André Breton. Sebbag explora las huellas bergsonianas en el surrealismo. O mejor: Sebbag, que investiga la superación surrealista de los dualismos, termina por hallar en uno de los capítulos de L’Amour fou, de André Breton, ciertos destellos de la concepción espaciotemporal bergsoniana. La expresión «mille et mille», a la que recurre Bergson en numerosas ocasiones en Essai sur les données immédiates de la conscience, en Matière et mémoire, también en libros posteriores, le hace ver la acción poética de Breton y los surrealistas en ese desplazamiento que viene del pasado y se prolonga en el porvenir, y a la inversa. A ello alude Sebbag con ese «mil y mil» imágenes, «mil y mil» recuerdos, «mil y mil» analogías, y que sugiere simbólicamente la duración de una experiencia creativa, poética, estética; también, la manera de comportarse de la memoria. Es en «Le château étoilé», publicado por Breton en la revista Minotaure y recogido luego como capítulo de L'amour fou, donde se entrelazan los recuerdos de lugares, de imágenes, de distintos momentos, constituyéndolos en la simultaneidad azarosa de lo escrito. Los surrealistas no dificultan el libre curso de la analogía y de la memoria. "Le château étoilé», cabe recordar, evoca la visita de André Breton a Tenerife en 1935, poco después de haber visitado el Castillo de la Estrella, muy próximo a Praga. Sobre ello, a la luz de Matière et mémoire, habla Sebbag en el capítulo «Mille et mille fois» de Le point sublime (1997: 89-99). Sobre esto volverá con mayor extensión y nuevas perspectivas en apartados diversos de Potence avec paraton- 
nere. Surréalisme et philosophie: «Le rôle de la mémoire», «Les durées automatiques» y «La pétrification du temps» (donde se refiere, además, a los cuadros de Domínguez y las superficies litocrónicas) y «Mille et mille fois» (Sebbag 2012).

Es Sebbag quien muestra, a partir de sus investigaciones en la obra de Breton, la apertura bergsoniana que se halla en Agustín Espinosa.

En efecto, casi al mismo tiempo que publica Le point sublime, Sebbag se traslada a Tenerife a impartir la conferencia «Le chapiteau étoilé». La intervención se publicaría al año siguiente, en 1998, en la revista Mélusine, y, poco después, ya en 1998, en Internacional constructivista frente a Internacional surrealista, traducida con el título "La carpa estrellada», y desposeída del juego de palabras chapitean étoilél château étoilé (Sebbag 1998: 25-37). Sebbag va a volver sobre lo planteado en Le point sublime, sobre el cono de la memoria de Bergson, sobre Matière et mémoire, y específicamente sobre Agustín Espinosa. Aquel «mil y mil» bergsoniano que traía datos inmediatos del pasado que se agolpaban en el presente -o en palabras de Bergson: «Aux données immédiates et présentes de nos sens nous mêlons mille et mille détails de notre expérience passée» (Matière et mémoire: 32) - se expresa, señala Sebbag, con igual intensidad en las referencias a "veinte» $\mathrm{y}$ "veinte» que se esparcen por los fragmentos de Crimen, y que acaso pudieron influenciar en la redacción del texto bretoniano (Sebagg 1998: 34). Espinosa, cabe recordar, acompañó y tradujo a Breton en su estancia en Tenerife durante 1935. A la alusión obsesiva de "mille et mille fois» equivale, señala Sebbag, el «veinte» espinosiano del comienzo del fragmento «Luna de miel»: «Me había dormido entre veinte senos, entre veinte bocas, veinte sexos, veinte muslos, veinte lenguas, veinte ojos de una misma mujer». Sobre esta percepción simbólico-numérica y sobre el cono de la memoria descrito en Matière et mémoire, regresa todavía George Sebbag más tarde (2000: 83).

Impresiones sucesivas: durée, duración. El simultaneísmo, sugerido ya en la actividad crítica, en los ejercicios hermenéuticos espinosianos, en los territorios cercanos al cubismo o del imagism, sale de cierta asepsia estética e intelectual y se precipita por los caudales inesperados de la analogía, la belleza convulsiva y provocadora del surrealismo. Crimen aparece en 1934. Todo ha cambiado: la durée que permitía establecer lazos sucesivos sobre personajes, palabras e imágenes en Lancelot avanza del lado de una voluptuosidad poética que establece «mil y mil» relaciones arbitrarias, y que intencionadamente se superpone en la concepción estética, filosófica, de une duración. La simultaneidad aparece y se disipa, se alza y se pone en juego, se afirma y se contradice en su rotundidad sensorial, a veces como Breton en L'amour fou, afirmando su dimensión táctil, a veces poniendo en juego, en un arbitrario y absurdo asociacionismo, la propia condición que proviene de la aceptación de la misma durée.

En Crimen puede verse en diversos sentidos, hacia el sujeto, hacia el personaje que narra y que se ramifica en presencias en el tiempo; hacia su María Ana; hacia la dimensión táctil que evoca Bergson; hacia la aproximación de palabras que dibujan instantes diversos de una percepción.

Veamos su manera de prolongar el pensamiento bergsoniano, aquel «nous promenons la main le long d'une surface», antes citado, que se superpone la experiencia táctil y que acoge toda una duración: 
Sentía una ternura que me llevaba a acariciar todas las cosas: lomos de libros, filos de navajas, hocicos de gato, rizos de pubis, prismas de hielo, cucarachas mohosas, lenguas de perro y pieles de marta, gusaneras y bolas de cristal...

una ternura que me llevaba a acariciar todas las cosas: picaportes, barandas de escalera, frutas podridas, relojes de oro, excrementos de enfermo, bombillas eléctricas, sostenes sudorosos, rabos de caballo, axilas peludas y camisetas sangrientas, pezones, copas de cristal, escarabajos... (Espinosa 1985: 63-64).

Veamos la misma presencia de las manos, ese frotar o estar cerca de sensaciones y de instantes diversos, que cruza la durée de su Crimen, y que subvierte, con su inclusión, la racionalidad de una narración o de una clásica composición musical, esto es, veamos cómo la duración de las sucesiones Primavera, Verano, Otoño, Invierno, tan tradicionales, son atravesada por gestos y caricias, por un paseo ("promenade») a través de zonas propias del imaginario surrealista, y que pueden recordar a Dalí, o al motivo de la mano que asciende y aparece en la portada que Óscar Domínguez realizó para la primera edición de Crimen (y que está en su teoría litocrónica).

Unas finas manos de mujer florecían sobre mis pies como dos clavos blancos... mis manos clavadas a la cama por dos anchos puñales...

mis senos, acariciados hoy por manos de ángeles... (Primavera).

¿Qué sabe nadie, qué sabemos nosotros, del puñal que nos herirá, de las manos que nos estrangularán, de la bala que nos estallará la cabeza? (Verano).

Una mano mutilada y única. Pálida, fría. Una mano olvidada ya de que fue mano de amante. Una mano angustiosamente blanca (Otoño).

¿Cuánto tiempo había permanecido cerrado el trágico balcón? Lo abrí vacilante, pensando que aun habría sobre las maderas huellas de sus manos (Invierno).

¿De dónde ha venido ese grito que ha interrumpido de pronto la tarde y ha hecho volver a un mismo tiempo todos los ojos y todas las manos hacia un mismo punto vago y distante? (Epílogo en la isla de las maldiciones).

Crimen se desplaza en medio de una durée fragmentaria, entre intervalos, como los textos mismos del relato. Es de una vivencia irreverente de lo que habla Crimen, del tiempo, de los miedos y los terrores, del erotismo, del sueńo, y de la superación de contrarios, del interior y el exterior, lo consciente y lo subconsciente, del pasado y porvenir, de la realidad y la imaginación, todo eso que el cubismo no pudo simultanear por completo y que el imagism prolongó en activaciones de antiguas imágenes, palabras y textos (Villon, Cavalcanti, el Inferno). Es desde la percepción surrealista donde todo puede entremezclarse, el yo, el narrador, las diferentes y sucesivas imágenes de María Ana. Es ahí donde se vuelve subversivo, acaso como ya anotaba Bergson mucho antes. Escribe Espinosa:

Ella se masturbaba cotidianamente sobre él, mientras besaba el retrato de un muchacho de suave bigote oscuro. 
Se orinaba y se descomía sobre él. Y escupía -y hasta se vomitaba- sobre aquel débil hombre enamorado, satisfaciendo así una necesidad inencauzable y conquistando, de paso, la disciplina de una sexualidad de la que era la sola dueña y oficiante.

Ese hombre no era otro que yo mismo (1985: 53).

Hoy me parece todo como un cuento escuchado en la niñez, y, a veces, hasta dudo de que fuese yo mismo quien arrojó una noche por el balcón de su alcoba, bajo las ruedas de un expreso, a una muchacha de dieciséis ańos (1985: 54).

la cabeza de María Ana rodaba al suelo, arrastrando en su caída cuatro blandones encendidos que yo no había visto hasta entonces. En el cielo, que empezaba a hacerse apenas rosado, flotaba una gran cruz oblonga a cuyo alrededor volaban varios cuervos silenciosos como siniestro rebańo de ataúdes alados (1985: 60).

¿Era yo un caballo? (1985: 65).

«Yo, medico titular de este pueblo, certifico que el paciente falleció a consecuencia de una peritonitis producida, al parecer, por coces recibidas de su caballo Agustín» (1985: 65).

en medio de la plaza solitaria donde yo era todavía mi estatua (1985: 79).

«Y yo no he traído hasta aquí -escribo- ni sus muslos de nieve, ni sus manos hábiles, ni siquiera sus ojos desmesuradamente abiertos dentro de un estuche sin leyenda...».

Vaga en el aire un alto oro de ausencia, como vigilia del alma en pena, o sueño de nińo agonizante, en lucha silenciosa con el paisaje y los recuerdos (1985: 93).

Recuerdos, sucesiones, encuentros de un sujeto que se dispersa entre diversos fragmentos e instantáneas, en medio de una mujer, María Ana, con diversos rostros, de un sujeto que se dispersa entre asociaciones de imágenes, de "promenades» por el interior de la memoria. Bergson se había expresado así, entendiendo que la idea de durée podía ser llevada hasta el absurdo. Así lo indicó en Essai sur les données immédiates de la conscience:

L'associationniste réduit le moi à un agrégat de faits de conscience, sensations, sentiments et idées. Mais s'il ne voit dans ces divers états rien de plus que ce que leur nom exprime, s'il n'en retient que l'aspect impersonnel, il pourra les juxtaposer indéfiniment sans obtenir autre chose qu'un moi fantôme, l'ombre du moi se projetant dans l'espace (Essai...: 148).

[El asociacionismo reduce el yo a un agregado de hechos de conciencia, sensaciones, sentimientos e ideas. Pero, si no se ve en esos diversos estados nada más que lo que su nombre expresa, si no se retiene de ellos más que su aspecto impersonal, podrá yuxtaponerlos indefinidamente sin obtener otra cosa que un yo fantasma, la sombra del yo que se proyecta en el espacio].

En efecto, la subversión de Espinosa consiste en mantener el lado inquietante del yo, como en una sombría figura de un cuadro de De Chirico; y de persistir 
por un momento en ese yo fantasmal, en esa hora crepuscular que atraviesa Crimen. En su libro persisten diversas durées - basta leer el fragmento "La mano muerta", o el comienzo de "Diario entre dos cruces»: «Van a mi espalda los peores adioses. Van ladridos de perros detrás de mi sombra, detrás del sudor caído en el polvo. Y todavía. Una cortina rota. Un sueńo encadenado. Una tormenta ejemplar. Un toro enfermo. Un río de sangre» (71). Basta leer el libro de esta perspectiva para encontrar que la osadía, como adelantaba Bergson, está en «desgarrar la tela hábilmente tejida por nuestro yo convencional»:

Que si maintenant quelque romancier hardi, déchirant la toile habilement tissée de notre moi conventionnel, nous montre sous cette logique apparente une absurdité fondamentale, sous cette juxtaposition d'états simples une pénétration infinie de mille impressions diverses qui ont déjà cessé d'être au moment où on les nomme, nous le louons de nous avoir mieux connus que nous ne nous connaissions nousmêmes (Essai...: 119).

[Pero si ahora un novelista osado, desgarrando la tela hábilmente tejida por nuestro yo convencional, nos muestra bajo esta lógica aparente un absurdo fundamental, bajo esta yuxtaposición de estados simples una penetración infinita de mil impresiones diversas que han dejado ya de ser en el momento en que se nombra, le alabamos por conocernos mejor de lo que nosotros nos conocemos a nosotros mismos].

Para Sebbag, como hemos indicado, la coincidencia del surrealismo y de Espinosa con ciertas ideas de Bergson, con ese «mil y mil», "veinte y veinte», que evocan la simultaneidad y el desplazamiento desde la memoria, resulta visible. ¿Espinosa estuvo cerca de Bergson? Nuestro autor conocía de una u otra forma el pensamiento bergsoniano. El escritor francés había estado en la Residencia de Estudiantes en 1916 y había sido estudiado por García Morente en un libro de 1917. También su Ensayo sobre los datos inmediatos de la conciencia fue traducido y reeditado en 1925 (Bergson 1925). Henri Bergson, por lo demás, obtuvo el premio Nobel de Literatura en 1927. ¡Cómo no conocerlo! Bergson formaba parte, además, del discurso y el debate sobre "les durées artificielles»: el cinematógrafo. $\mathrm{O}$ sobre la cuarta dimensión, presente en Durée et simultanéité. À propos de la théorie d'Einstein (1922). En cualquier caso, no es esto lo destacable. Lo importante es que, desde la perspectiva del comparatista, del hermeneuta, del creador cubista o surrealista, Espinosa instala en la durée recuerdos, interpretaciones, analogías, equivalencias, vínculos y creaciones. En el dominio de su ensayismo crítico subraya la duración de una amplia cultura que llega con sus imágenes y mitos antiguos, en su despliegue entre los siglos. En el dominio del hermeneuta funda un territorio de recordaciones que se extiende en el tiempo, supera su época y llega hasta nosotros. Se trata de una fundación verbal, una creación del lenguaje, que es la suya, pero también la de una lengua y de una cultura europea que se desplaza hacia Occidente: Atlántico adentro. Todo ello converge en Lancelot y en sus artículos, también en Crimen y en su «Isla de las maldiciones»; pero desde una órbita perturbadora, desde el desgarro del tejido de un yo convencional.

En una duración que afecta a la memoria y la subvierte, Crimen está ya del lado de la sensibilidad postcubista, del lado de un surrealismo que se ha expresado 
desde otros cauces, ya con las expectativas utópicas e historicistas del marxismo o del anarquismo, con irreverencias de todo tipo, con automatismos y un talante humorístico que pocas cosas va a dejar sin desbaratar: el crimen, las nociones tradicionales de la vida, del sueño, las ideas de lo sublime, del amor y de la belleza.

Aun cuando el pensamiento bergsoniano abre vías que todavía se exploran al calor de Deleuze, de Jankélévitch, de Sebbag, las actitudes contra el autor de Matière et mémoire son intensas en la época de Espinosa. Salvador Dalí lo consideraba un «porc». Magritte pinta en 1938 La Durée poignardée: La Duración apuñalada. Óscar Domínguez y Ernesto Sábato hablan desde la revista Minotaure de sucesión espaciotemporal, de cuarta dimensión, de movimiento sucesivo de unas manos sobre una superficie, y lo hacen con tono humorístico (Breton 1939: 12-13). No muy lejos tienen los planteamientos de Bergson. Domínguez, además, realiza en esta misma época Le souvenir de l'avenir (1938), o el cuadro Lancelot, $28^{\circ} 33^{\circ}(1939)$ en homenaje al libro de Espinosa. En otra dimensión, como en el desplazamiento de la mano sobre el violín o sobre cualquier otra superficie, Domínguez muestra una durée de naturaleza cósmica en sus cuadros, y se refiere a ello como "solidificaciones del tiempo" (Palenzuela 1999: 85-100). En la misma línea, con el mismo humor, acaso con risa bergsoniana, Espinosa dilata su escritura, proyecta hacia el futuro una obra que se abre todavía ante nosotros, con nuevas aristas de recepción, desde el cine, desde el teatro, desde la fotografía, desde la literatura, desde la música. Agustín Espinosa dilata su duración y la de toda una cultura. 


\section{BIBLIOGRAFÍA}

Armas Ayala, Alfonso y Miguel Pérez Corrales (1980): Agustín Espinosa. Textos (1927-1936), Santa Cruz de Tenerife: Aula de Cultura de Tenerife.

Bergson, Henri (2011a): Essai sur les données immédiates de la conscience, edition numérique: Pierre Hidalgo, La Gaya Scienza. URL: http://www.ac-grenoble.fr/PhiloSophie/old2/file/bergson_essai_conscience.pdf [fecha de consulta: 15/01/2020].

Bergson, Henri (2011b): Matière et mémoire. Essai sur la relation du corps à l'esprit, edition numérique: Pierre Hidalgo, La Gaya Scienza, décembre 2011. URL: http://www.ac-grenoble.fr/ PhiloSophie/old2/file/bergson_matiere_et_memoire.pdf [fecha de consulta: 20/01/2020].

Breton, André (1939): «Des tendances plus récentes de la peinture surréaliste», Minotaure 12-13: $16-24$.

FAUChereau, Serge (2002): «Quelques semaines au printemps de 1935: l'Internationale surréaliste», en La Révolution Surréaliste, Paris: Centre Pompidou, 403-411.

Fauchereau, Serge (2010): Avant-gardes du XXe siècle. Arts \& Littérature. 1905-1930, Paris: Flammarion.

Fauchereau, Serge (2012): Le cubisme. Une révolution esthétique. Sa naissance et son rayonnement, Paris: Flammarion.

Flahutez, Fabrice (2012): «Portrait analogique et figure du poète Garcia Lorca selon Roberto Matta», en Fabrice Flahutez, Itzhak Goldberg y Panayota Volti, Visage etlou portrait, Paris: Presses Universitaires de Paris Nanterre, 97-108. URL: https://books.openedition.org/pupo/960 [fecha de consulta: 10/11/2019].

Gómez Gutiérrez, Beatriz (2008): Les mythes et leurs métamorphoses dans l'oeuvre d'Agustín Espinosa (1897-1939), Paris: Université Paris-Sorbonne.

Palenzuela, Nilo (1988a): Introducción, Lancelot, $28^{\circ}-7^{\circ}$, Santa Cruz de Tenerife: Interinsular Canaria.

Palenzuela, Nilo (1988b): «La isla recordada de Domínguez», Jornada, Santa Cruz de Tenerife, 15/10/1988.

Palenzuela, Nilo (1994): «Cubismo y neogongorismo en las poéticas narrativas de los años veinte», FGL. Boletín de la Fundación Federico García Lorca 16: 113-127.

Palenzuela, Nilo (1999): «Óscar Domínguez: paisajes del deseo», en Visiones de Gaceta de Arte, Las Palmas de Gran Canaria: Ediciones del Cabildo Insular de Gran Canaria, 55-100.

Palenzuela, Nilo (2006): "Agustín Espinosa y el mito. Un ejercicio hermenéutico», en Encrucijadas de un insulario, Santa Cruz de Tenerife: Ediciones Idea, 117-156.

Pérez Corrales, Miguel (1985): Introducción y edición. Crimen, Santa Cruz de Tenerife: Interinsular Canaria.

Pérez Corrales, Miguel (1986): Agustín Espinosa, entre el mito y el sueño, I-II, Las Palmas de Gran Canaria: Ediciones del Cabildo Insular de Gran Canaria.

Pérez Corrales, Miguel (2019a): Espinosa, obra en libertad. URL: https://espinosaobraenlibertad. blogspot.com/2019/06/obra-en-libertad.html [fecha de consulta: 11/01/2020].

Pérez Corrales, Miguel (2019b): «Caleidoscopio surrealista y otros estudios», en Surrealismo internacional. URL: http://surrint.blogspot.com/2019/07/agustin-espinosa-obra-en-libertad. html [fecha de consulta: 22/01/2020]. 
Sebbag, Georges (1997): Le point sublime. Breton, Rimbaud, Kaplan, Paris: Jean Michel Place.

Sebbag, Georges (1999): «La carpa estrellada», en M. ${ }^{2}$ Isabel Navarro Segura (ed.), Internacional constructivista frente a Internacional surrealista, Santa Cruz de Tenerife: Cabildo Insular de Tenerife, 25-37. Antes: «Breton aux Canaries. Le chapiteau étoilé», Mélusine, 18 (L’Âge d'homme, 1998). URL: http://www.philosophieetsurrealisme.fr/breton-aux-canaries-lechapiteau-etoile/ [fecha de consulta: 25/10/2019].

SebbaG, Georges (2000): «La edad de oro de los surrealistas», en Emmanuel Guigon (ed.), Luis Buñuel y el surrealismo, Teruel: Museo de Teruel, 81-95.

Sebbag, Georges (2012): Potence avec paratonnere. Surréalisme et philosophie, Paris: Harmann.

Thibault, Alexandre (2006): La durée picturale chez les cubistes et futuristes comme conception du monde: suggestion d'une parenté avec le problème de la temporalité en philosophie, Québec: Université Laval. 